\title{
Encephalitozoon cuniculi infection in farmed rabbits in Egypt
}

\author{
Eman Anter Morsy' ${ }^{1}$ Heba Mohammed Salem¹, Marwa Salah Khattab², Dalia Anwar Hamza ${ }^{3}$ \\ and Mai Mohammed Abuowarda ${ }^{4^{*}}$ (i)
}

\begin{abstract}
Background: Encephalitozoon cuniculi is an important microsporidian parasite with zoonotic potential. The present study highlights the impact of encephalitozoonosis on rabbit health in Egypt. Three rabbit farms in Giza, with a total of 16,400 rabbits were investigated due to occurrence of rabbits displaying clinical signs consistent with encephalitozoonosis.

Results: Clinical signs observed during a 4 months observation period in 2018 included vestibular disease, paresis, limb paralysis, cataracts, phacoclastic uveitis, frequent urination, marked decrease in body weight and in some pregnant females, also repeated abortions. The total morbidity rates in adult and young rabbits were $76.7 \%$ and $81.5 \%$, respectively. The highest mortality rate was recorded in offspring (12.3\%), followed by dams (5.6\%), and the lowest recorded mortality rate was in males (0.04\%). Post-mortem findings included enteritis, pale enlarged kidneys, congested leptomeninges, focal brain necrosis, and endometrial congestion. Histopathological examination revealed nonsuppurative meningoencephalitis and glial nodules with central necrosis in the brain, vacuolation and necrosis of renal tubular epithelium, and corneal ulceration and ruptured lens capsule with fragmentation of lenticular fibres. $E$. cuniculi were observed in the brain, retinal ganglion cells, kidneys, and liver. Transmission electron microscopy examination revealed the presence of different developmental stages of E. cuniculi in the brain and kidney. Presence of $E$. cuniculi was confirmed by conventional polymerase chain reaction using a universal 165 gene for Encephalitozoon spp. followed by sequencing and sequence analysis.
\end{abstract}

Conclusions: The presence of E. cuniculi in rabbits was confirmed at three farms in Egypt. Nervous signs and ocular lesions were the most predominant findings in these farms.

Keywords: Encephalitozoon cuniculi, Histopathology, Incidence, Polymerase chain reaction, Rabbit, Transmission electron microscopy

\section{Background}

Encephalitozoon cuniculi is an obligate intracellular spore-forming protozoan parasite belonging to the phylum Microsporidia, which contains approximately 1400 species distributed into about 200 genera. E. cuniculi can infect almost all invertebrates and vertebrates, as well

*Correspondence: mai.abuowarda@cu.edu.eg

${ }^{4}$ Department of Parasitology, Faculty of Veterinary Medicine, Cairo University, PO Box 12211, Giza, Egypt

Full list of author information is available at the end of the article as some protists [1]. E. cuniculi, which was first identified in 1922 in a colony of research rabbits in the USA, is now recognized as a common pathogen and a significant cause of disease among pet rabbits [2-4]. E. cuniculi has a zoonotic potential, especially for immunocompromised adults and for children [5]. Therefore, E. cuniculi has received increased attention [6], and hygienic precautions should be undertaken when humans are in contact with rabbits or rabbit products [7].

The life cycle of E. cuniculi takes 3 to 5 weeks to complete [8]. Hosts are infected by ingestion or inhalation of 
spores or by transplacental transmission [9]. After ingestion, the spores invade enterocytes and then enter the bloodstream or the lymphatic system, possibly through Peyer's patches or interepithelial lymphocytes, and thereafter reach organs such as the brain, kidney and liver. Spores can also transmigrate after having been ingested by phagocytes present in the intestinal mucosa [10]. Infected rabbits develop serum antibodies generally within 3 weeks post-exposure and excrete E. cuniculi by 6 weeks [11]. The spores are excreted through urine and faeces; hence, transmission generally takes place after the ingestion of water or food contaminated with infective spores [5].

Encephalitozoon cuniculi infection of the central nervous system is associated with development of vestibular disease, which is characterized by torticollis, ataxia, paresis, nystagmus, seizures, and longitudinal rolling and the animal often becomes recumbent $[12,13]$. In addition to nervous signs, infected rabbits develop eye lesions and chronic renal failure [14]. In the eye, inflammation of the anterior lens capsule can lead to its spontaneous rupture. Moreover, phacoclastic uveitis develops because of perilenticular fibroplasia together with lens capsule rupture $[15,16]$. Kidney lesions can be observed within 4 weeks, and brain lesions within 8 weeks after infection [17]. Microscopic lesions in the brain and kidney, consist of focal non-suppurative granulomatous meningoencephalitis and focal to segmental interstitial nephritis with varying degrees of fibrosis [18].

Transmission electron microscopy (TEM) can be used to confirm encephalitozoonosis by detecting the polar filament within spores and demonstrating ultrastructural features. TEM, along with newly applied molecular approaches, can contribute to the taxonomic organization of the microsporidia [19, 20]. Polymerase chain reaction (PCR)-based methods that typically utilize primers for amplification of microsporidial rDNA have been commonly utilized to enhance diagnostic sensitivity and specificity; however, they are still not routinely used in diagnostic laboratories [21]. The E. cuniculi genome is very small being only $2.9 \mathrm{Mb}$ large and compressed. It harbours 2000 genes that are located within minute intergenic regions (the mean intergenic region is $80 \mathrm{bp}$ ) [22]. Analyses of genome diversity have revealed the existence of four genotypes of E. cuniculi (EcI, II, III and IV) [23].

Rabbit production recently has become well established in Egypt, but little is known about the exact rabbit numbers. Most of the rabbit population in Egypt is in the hands of smallholders, while the rest belongs to the commercial sector as a good source of protein [24]. Rabbits are also used for medical purposes such as the diagnosis of infectious diseases, production of vaccines and other biological substances of public health and veterinary importance [25]. Parasites are responsible for direct and indirect losses of rabbits that are attributed to acute illness and death, premature slaughter, decreased growth rate, weight loss and late maturity of slaughter stock [26].

In Egypt, E. cuniculi was not reported until 2011, when its presence was indicated by serological screening of the domestic rabbit population in northern Egypt, in Behera, Alexandria and Khafr El-Sheikh for E. cuniculi and Toxoplasma gondii [7]. However morphometric or pathological investigations have not yet been carried out.

The purposes of this study were (1) to investigate encephalitozoonosis in rabbit farms in middle Egypt; (2) to confirm the presence of E. cuniculi using pathology and molecular techniques and (3) to describe clinical signs, histopathological changes, morphology features and genetic characteristics of the parasite.

\section{Methods \\ Animals}

Three commercial rabbit farms $(\mathrm{A}-\mathrm{C})$ in the Giza governorate in middle Egypt, with a total of 16,400 rabbits (4121, 5583 and 6696 rabbits for each of the three farms, respectively) founded the study population. Rabbits on these farms were investigated during a 4 months period in 2018.

Rabbits that exhibited clinical signs suggestive of $E$. cuniculi infection $(\mathrm{n}=13,242)$ underwent a clinical examination. Of these 13,242 rabbits, 2680, 4658 and 5904 rabbits came from farms A, B and C, respectively.

Rabbits of different breeds, including New Zealand, Chinchilla, and Californian, were reared in a wire net cage system and fed commercial pellets. Rabbit handling procedures were performed in accordance with the applicable legislation of the Institutional Animal Care and Use Committee of the Faculty of Veterinary Medicine, Cairo University, Egypt (VetCU11112018015).

The examined animals were classified into two age groups, i.e. young and adults. Young rabbits $(n=11,170)$ were from 0 to 4 months old, whereas adults $(n=2072)$ were rabbits older than 4 months and up to 1 year old. Of the adult rabbits, 332 were males and 1740 females.

\section{Clinical examination}

The rabbits were visually assessed from a distance and any abnormal behaviour was recorded. Each visual assessment took about $5 \mathrm{~min} / \mathrm{cage}$. If abnormal behaviour was observed, the rabbit was taken out of the cage and examined according to [27]. This consisted of inspection of the head, including ears, eyes, nose, mucous membranes and lymph nodes and abdominal palpation of the stomach, small intestines, caecum, colon, kidneys, bladder and the uterus. Finally, the perineum and limbs were examined. Securing of the rabbits was performed by 
placing them sitting in a compact posture while placing two hands lightly over their shoulders.

\section{Post mortem examination and sample collection}

Necropsy was performed on two subgroups of rabbits: (1) rabbits with severe clinical signs that were euthanized and (2) rabbits that had died shortly before a farm visit. The number of required euthanised rabbits was calculated to 376 by using the Open EPI free software https:// www.openepi.com/SampleSize/SSPropor.htm and a confidence level of $95 \%$. However, the owners only allowed euthanasia of 341 rabbits. These were anaesthetized by intramuscular injection of ketamine $(30 \mathrm{mg} / \mathrm{kg})$ and xylazine $(5 \mathrm{mg} / \mathrm{kg})$ and then euthanized by exsanguination [28]. The group of recently dead rabbits consisted of 830 animals.

Samples for laboratory analyses were taken from 30 of the euthanized rabbits and from 20 of the recently dead rabbits from each farm giving a total number of 150 rabbits. These 150 rabbits were selected randomly from each farm among necropsied rabbits with prominent lesions indicating encephalitozoonosis. The following laboratory examinations were performed: (1) histopathology was performed on 10 rabbits from each of the three farms, (2) TEM was performed on seven rabbits, and (3) PCR was done on all 150 rabbits.

\section{Histopathological examination}

Specimens of the brain, kidney, liver, and eye from the 30 rabbits were fixed in $10 \%$ neutral buffered formalin. The samples were then processed, paraffin-embedded, sectioned at $3 \mu \mathrm{m}$ thickness and stained with haematoxylin and eosin and Giemsa stain [29].

\section{Transmission electron microscopy examination}

Brain and kidney specimens from the seven rabbits were fixed in $2.5 \%$ glutaraldehyde, kept for $4 \mathrm{~h}$ at $4{ }^{\circ} \mathrm{C}$, thoroughly rinsed overnight at $4{ }^{\circ} \mathrm{C}$ in $0.1 \mathrm{M}$ phosphate buffer, fixed in $1 \%$ osmium tetraoxide $\left(\mathrm{OsO}_{4}\right)$ for $30 \mathrm{~min}$ at $4{ }^{\circ} \mathrm{C}$, then washed in PBS ( $\mathrm{pH}$ 7.3) for $1 \mathrm{~h}$ followed by dehydration in an ethanol gradient (50-90\% for $15 \mathrm{~min}, 100 \%$ for $1 \mathrm{~h}$ ). The samples were then routinely processed and embedded in Epon-Araldite. Semithin sections $(0.5 \mu \mathrm{m})$ were cut with a glass knife using a microtome (RMC Inc., Tucson, AZ, USA) and collected on copper grids and then stained with $1 \%$ toluidine blue for $20 \mathrm{~min}$, washed in distilled water and placed in Permount. The obtained slides were examined and photographed using an Olympus DP20 microscope (Olympus, Tokyo, Japan) [14]. Ultrathin sections were stained for 15 min with a saturated uranyl acetate solution and counterstained in lead citrate for $20 \mathrm{~min}$ (thickness 500-700 Angstrom). Grids containing ultrathin sections of the material were analysed and photographed using a JEM-1200 EX II transmission electron microscope (Jeol, Tokyo, Japan). This was performed at the Electron Microscope Unit at the Military Veterinary Hospital in Nasr City, Cairo, Egypt.

\section{DNA extraction}

DNA was extracted from brain, eyeball, liver, and kidney of the 150 rabbits using the DNeasy Blood \& Tissue Kit (Qiagen, Düsseldorf, Germany) according to the manufacturer's instructions.

PCR was performed for the target regions of the small subunit of $16 \mathrm{~S}$ rRNA of zoonotic microsporidia, including E. bieneusi, E. intestinalis, E. cuniculi, E. hellem, Vittaforma corneae, and Pleistophora spp. using the forward primer F (5'-CAC CAG GTT GAT TCT GCC TGAC-3') and reverse primer $\mathrm{R}\left(5^{\prime}\right.$-CCT CTC CGG AAC CAA ACC CTG-3') [30]. These primers are designed to generate amplicons of $260 \mathrm{bp}$. The amplification was performed using reaction conditions according to [30].

\section{Sequencing of PCR products and sequence analysis}

Among the PCR positive products, 10 samples representing three from each of farm $A$ and $B$ and four from farm $C$ were purified using the QIAquick purification kit (Qiagen) according to the manufacturer's instructions and sequencing was conducted using the Big Dye Terminator V3.1 Sequencing kit (Applied Biosystems, Waltham, USA) with the forward and reverse primer for 16S rRNA. The obtained 10 nucleotide sequences were aligned with the sequences in GenBank using the NCBI BLAST server to confirm the identity with E. cuniculi.

The sequence (177 bp) of the E. cuniculi $16 \mathrm{~S}$ ribosomal RNA gene was deposited in GenBank, Accession number MK615616.

The submitted gene sequence was compared with the aligned sequences available in the NCBI GenBank database. Publicly available $16 \mathrm{~S}$ rRNA gene sequences for $E$. cuniculi were downloaded from the NCBI GenBank and imported into BioEdit version 7.0.1.4 for multiple alignments using the ClustalW program in BioEdit. A similarity matrix was done using the DNASTAR program (Lasergene, version 8.0). The genetic distance values of species variations of $E$. cuniculi were analyzed with MegAlign project of DNSTAR software.

\section{Results}

\section{Clinical findings}

Signs of central vestibular disease were observed in $81.5 \%$ of the 13,242 rabbits and consisted of ataxia, circling or rotation around the longitudinal axis, head tilt (Fig. 1a) and paresis or paralysis in the forelimbs (Fig. 1b) and hindlimbs (Fig. 1c). Eye lesions, mostly unilateral, were 

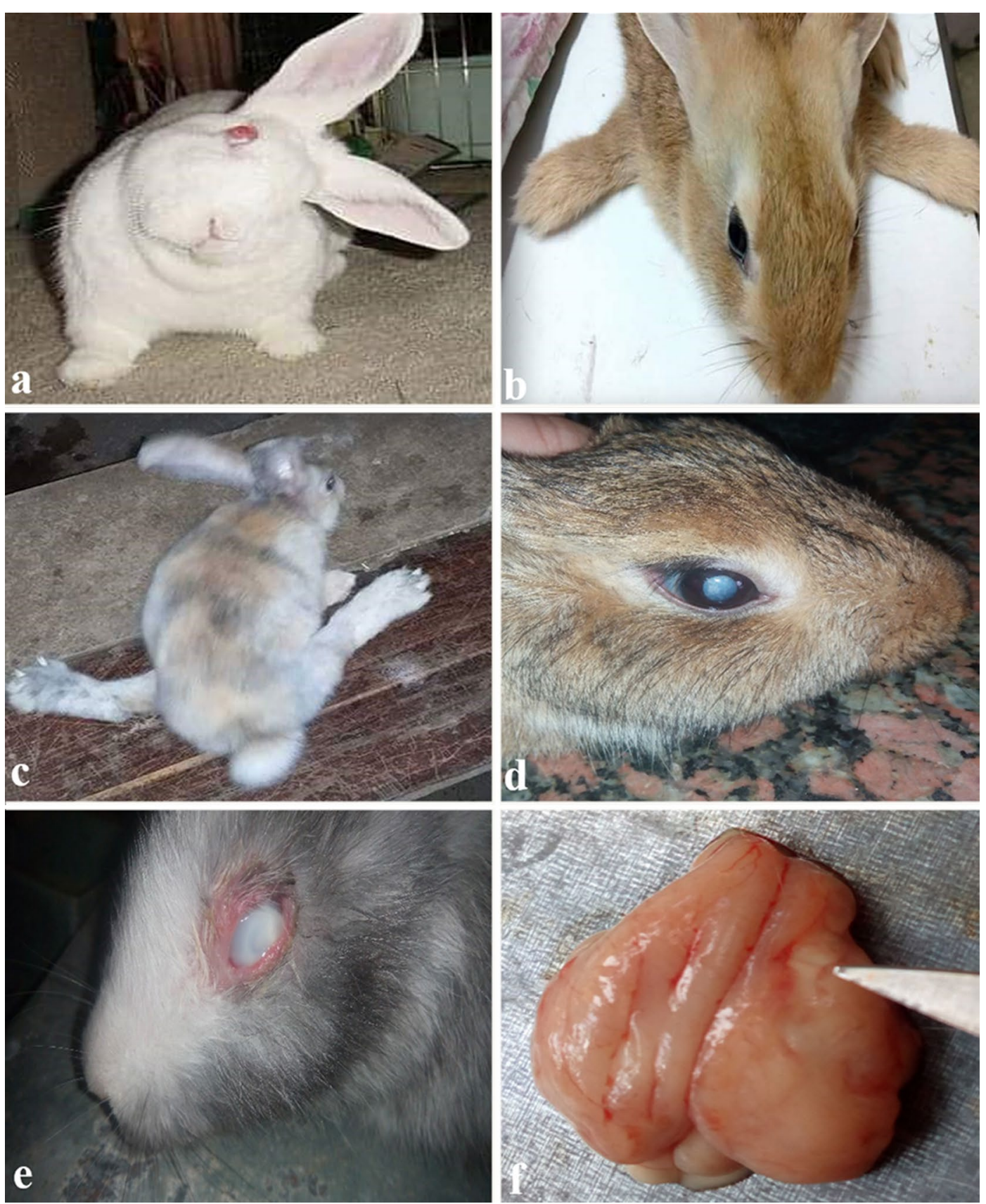

Fig. 1 Photographs of clinical and postmortem findings of rabbits infected with E. cuniculi showing a head tilt in adult rabbit, b forelimb paralysis in young rabbit, $\mathbf{c}$ hind limb paralysis in young rabbit, $\mathbf{d}$ mild unilateral cataract in right eye, e severe unilateral cataract in left eye, and $\mathbf{f} c e r e b r a l$ focal necrosis and congested leptomeninges

found in $10.5 \%$ of the rabbits and were characterized by cataracts and phacoclastic uveitis (Fig. 1d, e). Polyuria, diagnosed by urine scalding of posterior limbs and dehydration, occurred in $2.7 \%$ of the rabbits. Additional nonspecific clinical signs such as lethargy, anorexia and/or weight loss or a combination of these signs were observed in $5.2 \%$ of the rabbits, while $0.26 \%$ of the pregnant female rabbits had repeated abortions.

The clinical manifestation varied among animals of different sexes and age groups (Table 1). Morbidity and mortality rates varied among the three farms and between gender and age groups (Tables 2 and 3 ). 
Table 1 Incidence of different clinical signs in rabbits infected by E. cuniculi during the 4 months of observation (2018)

\begin{tabular}{lccccc}
\hline Rabbits & No. of rabbits & $\begin{array}{l}\text { Nervous manifestation head } \\
\text { tilt and leg paralysis (\%) }\end{array}$ & Eye lesions uveitis (\%) & Polyuria (\%) & $\begin{array}{c}\text { Combined and non- } \\
\text { specific symptoms (\%) }\end{array}$ \\
\hline Dam & 1740 & $1335(76.7)$ & $223(12.8)$ & $77(4.4)$ & $105(6.03)$ \\
Male & 332 & $250(75.3)$ & $55(16.5)$ & $16(5.1)$ & $11(3.3)$ \\
Young rabbits & 11,170 & $9210(82.4)$ & $1110(9.9)$ & $275(2.4)$ & $575(5.15)$ \\
Total & 13,242 & $10,795(81.5)$ & $1388(10.5)$ & $368(2.7)$ & $691(5.2)$ \\
\hline
\end{tabular}

Table 2 Morbidity and mortality rate recorded in adult rabbits during the 4 months of observation (2018)

\begin{tabular}{|c|c|c|c|c|c|c|}
\hline \multirow[t]{2}{*}{ Farms } & \multirow{2}{*}{$\begin{array}{l}\text { Total number of rabbits } \\
\text { in each farm }{ }^{\mathrm{a}}\end{array}$} & \multirow{2}{*}{$\begin{array}{l}\text { Total no. } \\
\text { of investigated } \\
\text { rabbits }\end{array}$} & \multicolumn{2}{|c|}{ Dams ( $>4$ months to 1 year) } & \multicolumn{2}{|c|}{ Males (>4 months to 1 year) } \\
\hline & & & Morbidity\% & Mortality\% & Morbidity (\%) & Mortality\% \\
\hline A & 756 & 450 & $370(48.9)$ & $20(2.6)$ & $80(10.6)$ & $0(0)$ \\
\hline B & 943 & 758 & $650(68.9)$ & $65(6.9)$ & $108(11.4)$ & $1(0.1)$ \\
\hline C & 1002 & 864 & $720(71.8)$ & $66(6.6)$ & $144(14.37)$ & $0(0)$ \\
\hline Total & 2701 & $2072(76.7)$ & $1740(64.4)$ & $151(5.6)$ & $332(12.3)$ & $1(0.037)$ \\
\hline
\end{tabular}

a Total number of rabbits in each farm including both apparently healthy and clinically affected rabbits

Table 3 Morbidity and mortality rate recorded in young rabbits (0 to 4 months) during the 4 months of observation (2018)

\begin{tabular}{lllllll}
\hline Farm & $\begin{array}{l}\text { Total number of newly } \\
\text { born rabbits }\end{array}$ & $\begin{array}{l}\text { Clinically affected } \\
\text { rabbits }\end{array}$ & Morbidity\% & \multicolumn{2}{l}{ Mortality (\%) } \\
\cline { 5 - 7 } & & & & Total & $\begin{array}{l}\text { Early before weaning } \\
\text { (PM) }\end{array}$ & $\begin{array}{l}\mathbf{>} \text { 2 month (with } \\
\text { clinical symptoms) }\end{array}$ \\
\hline A & 3365 & 2230 & 66.3 & $157(4.6)$ & $49(1.5)$ & $108(3.2)$ \\
B & 4640 & 3900 & 84 & $780(16.8)$ & $497(10.7)$ & $283(6.1)$ \\
C & 5694 & 5040 & 88.5 & $756(13.3)$ & $609(10.7)$ & $147(2.6)$ \\
Total & 13,699 & 11,170 & 81.5 & $1693(12.3)$ & $1155(8.4)$ & $538(3.9)$ \\
\hline
\end{tabular}

a Without clinical symptoms

\section{Postmortem findings}

Gross pathological changes were observed in $60.7 \%$ of the 1171 necropsied rabbits. Cataract and acute focal unilateral uveitis in the anterior chamber were observed in 362 rabbits (Fig. 1d, e). Brain lesions were recorded in 215 rabbits. Meningeal and cerebral vessels were congested with acute severe unilateral multifocal necrosis in the cerebrum (Fig. 1f). Pale enlarged kidneys were found in 84 rabbits with acute mild widespread necrosis of the medulla. Other findings such as endometrial congestion and otitis externa were also observed.

\section{Histopathological findings}

Microscopy of brain sections revealed severe diffuse non-suppurative leptomeningitis (Fig. 2a). In the cerebral cortex and medulla oblongata, multifocal gliosis, perivascular mononuclear cellular cuffing (Fig. 2b) and glial nodules were seen. Some glial nodules had central necrosis (Fig. 2c). Neuronal degeneration and neuronophagia was observed in glial nodules and scattered in the cerebral cortex. Intracellular and extracellular mature spores and pseudocysts that contained basophilic ovoid spores were observed in the cerebral cortex and hippocampus (Fig. 2d). In some rabbits, parasitic spores were found without any associated inflammation. In semithin sections, different stages of the parasite were seen (Fig. 2e, f). Moreover, Giemsa stained ovoid to rod-shaped bluish parasites were observed in neurons (Fig. 2g).

Microscopy of liver sections showed mild degeneration of hepatocytes in the centrilobular area and periportal mononuclear cellular infiltrates. Ovoid to rod-shaped bluish parasites were observed in the liver using Giemsa stain (Fig. 2h).

Microscopy of eye sections revealed epithelial ulceration, endothelial necrosis, and oedema of the cornea. The lens capsule was irregular and sometimes had fragmentation of lens fibres and lens epithelial cell necrosis. Infiltration with mononuclear cells was 

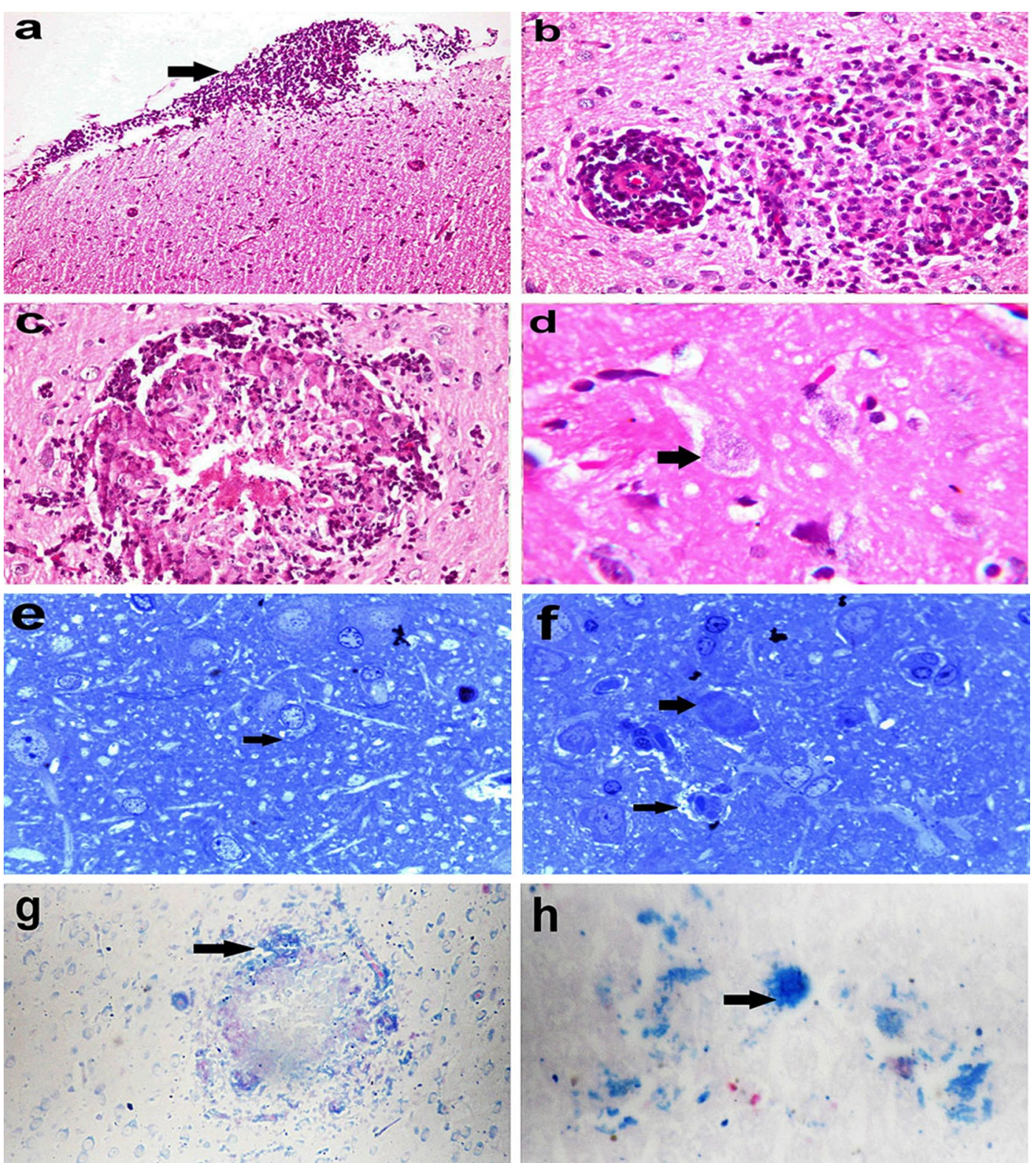

Fig. 2 Photomicrographs of E. cuniculi in the brain of rabbits. a Severe diffuse non-suppurative leptomeningitis and diffuse gliosis (H\&E. Obj $\times 20)$, b perivascular lymphocytic cuff and glial nodule, c glial nodule with central necrosis and rod to ovoid-shaped mature E. cuniculi spores, and $\mathbf{d}$ mature E. cuniculi spores intracellularly in neurons ( $\mathrm{H} \& \mathrm{E}, \mathrm{Obj} \times 40$ ), e parasitophorous vacuoles (arrows) and $\mathbf{f}$ free spores of E. cuniculi (arrow) by toluidine blue (Obj $\times 100)$, and $\mathbf{g}$ bluish-stained rod to ovoid-shaped E. cuniculi at the periphery of the glial nodule in the brain (Giemsa stain, Obj $\times 20)$, $\mathbf{h}$ liver with bluish-stained rod to ovoid-shaped E. cuniculi by Giemsa stain (Obj ×60)

observed in the corneoscleral trabecular meshwork, the junction between the cornea and conjunctiva, iridocorneal drainage angle and in the posterior chamber of the eye admixed with fibrin. The iris was oedematous, infiltrated with scattered mononuclear cells and showed degeneration of the posterior epithelium. The retina was atrophied and detached. Small basophilic rod-shaped parasites were seen in ganglion cells of the retina without associated inflammatory reaction (Fig. 3a).

Microscopy of kidney sections showed vacuolation and necrosis of the epithelium lining the convoluted tubules and collecting ducts. Small basophilic parasite spores $(0.6-1.08 \times 1.18-1.78 \mu \mathrm{m})$ were present inside tubular epithelial cells and were released in the tubular lumen with little or no associated inflammatory reaction 


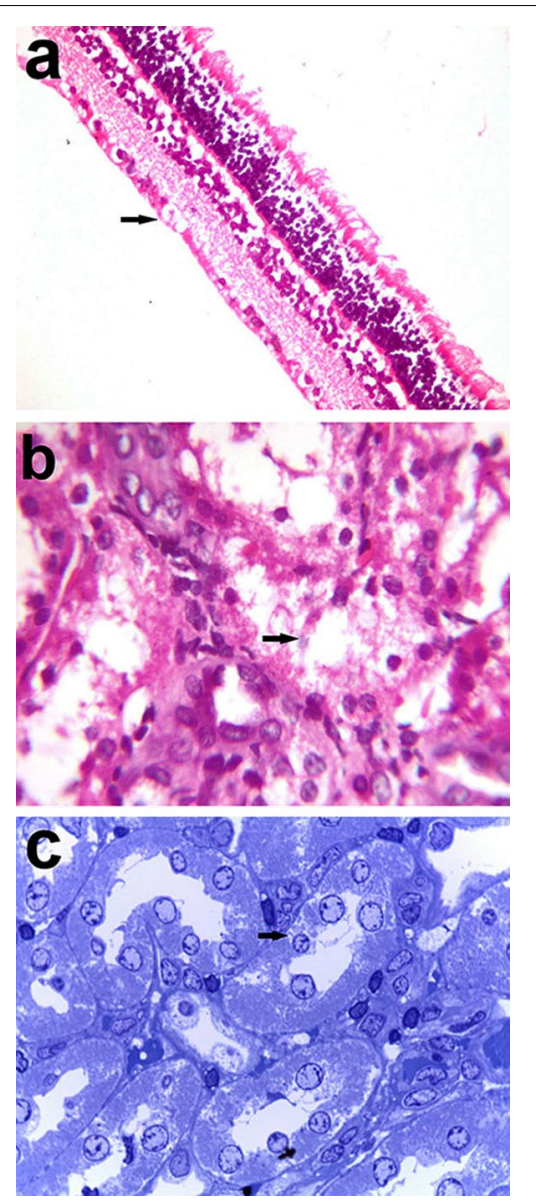

Fig. 3 Photomicrographs of the eye and kidney of rabbits infected with E. cuniculi. a E. cuniculi in ganglion cells of the retina (H\&E stain, Obj $\times 40)$, $\mathbf{b}$ vacuolation, and necrosis in epithelium of convoluted and collecting tubules of kidney with the presence of small basophilic rod-shaped E. cuniculi spores (H\&E stain, Obj $\times 100$ ), and c parasitophorous vacuole (arrows) in the renal tubular epithelium by toluidine blue $(\mathrm{Obj} \times 100)$

(Fig. 3b). In semi-thin sections, cysts containing ovoid parasitic spores were observed in the renal tubular epithelium with the displacement of the nuclei towards their apical surface (Fig. 3c). The spores were released from the apical surface of the tubular epithelium that showed pyknosis or karyolysis.

\section{TEM}

The meront, sporont, and sporoblast stages of E. cunic$u l i$ were all found in brain sections. The meront stage was ovoid with a size of $2.21-3.1 \times 3.175-3.8 \mu \mathrm{m}$, had an electron-lucent endospore layer and was surrounded by a dense outer coat. The sporont and sporoblast stages were also ovoid but measured only $1.91 \times 2.3 \mu \mathrm{m}$ and $1.85 \times 2.2 \mu \mathrm{m}$, respectively (Fig. 4).
Only the sporont stage and mature spores were detected in the kidney. They had a characteristic ovoid shape. The mature spores had lamellar polaroplast, with five single rows of coiled polar tubes surrounded by spore walls. The size of sporonts was $2.5-2.55 \times 4.2-3.85 \mu \mathrm{m}$, while a mature spore measured $1.75 \times 3.3 \mu \mathrm{m}$ (Fig. 5). E. cuniculi were found intracellularly and had different stages with different size located in the brain and kidney.

\section{Molecular findings}

All examined brain, kidney, eye and liver tissues were positive for the expected amplicon molecular weight (260 bp). The sequence analyses from the ten selected positive samples were identical and revealed a $100 \%$ similarity to E. cuniculi strains deposited in the GenBank database.

Inter- and intra-species analyses of genetic distance among the obtained sequence and other 11 aligned sequences available in the NCBI GenBank database of $E$. cuniculi were performed. (Fig. 6). The genetic identity of E. cuniculi had a high sequence homology (99.4\% similarity) with the Donovan sequence of E. cuniculi (Accession number X98470) isolated from a human in the UK (Fig. 6). Interspecies analysis based on the genetic distance values indicated a zero level of genetic divergence (GD) within the genospecies of E. cuniculi isolated from a human (Donovan sequence). However, the Donovan sequence of E. cuniculi was genetically more distant (GD $0.6)$ from $E$. cuniculi isolated from humans from the UK and USA (Accession numbers (X98467, L39107, L17072, and L7255).

\section{Discussion}

The rabbit industry in Egypt is at present flourishing and rabbits have become an alternative source for meat [24]. The transmission of E. cuniculi to rabbit farms threatens the fate of this industry due to high morbidity and a potential zoonotic risk [7]. The high morbidity of the disease in the three investigated farms indicates that this parasite was endemic in the farms. The high rate of infection may be due to the ingestion of contaminated food or water with $E$. cuniculi spores further spread through the urine of infected rabbits [12]. The difference in morbidity in the three investigated farms might be due to environmental factors and husbandry. Females had a higher morbidity rate $(64.4 \%)$ than males $(12.3 \%)$, which is contradictory to previous findings [31]. The highest morbidity rate was recorded in the young age group (81.5\%), which was similar to previous findings [31].

The diagnosis of diseases causing nervous signs in rabbits are challenging as they may be caused by many conditions. In the present study, the association of nervous signs with ocular lesions suggested 

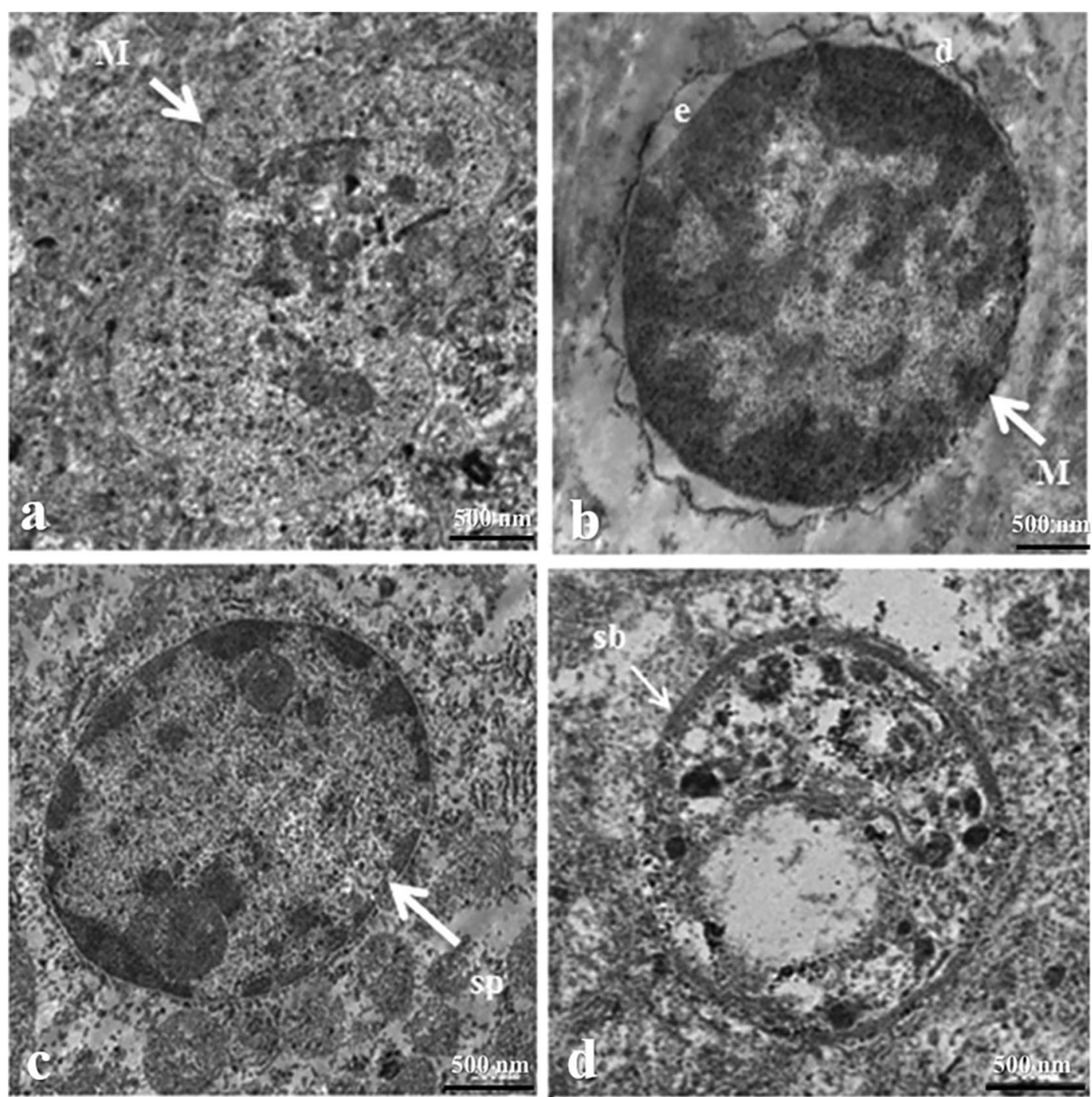

Fig. 4 Transmission electron micrographs of different stages of $E$. cuniculi in brain tissue from infected rabbits showing $\mathbf{a}$, $\mathbf{b}$ meront of different shape, $\mathbf{c}$ sporont, and $\mathbf{d}$ sporoblast (e electron-lucent endospore layer, $d$ dense outer coat, $M$ meront, sb sporoblast, sp sporont)

encephalitozoonosis. Nervous signs including central vestibular disease and unilateral ocular lesions are the main signs associated with E. cuniculi infection in rabbits [32-35] and leptomeningitis and necrotic foci in the brain are known as the main lesions associated with E. cuniculi [6] as also observed in the present study. The necrotic foci were mainly glial nodules with central necrosis as reported previously [36]. Brain lesions varied in severity between rabbits. The formation of glial nodules might be due to the chitin of endospore microsporidians as chitin is chemotactic for macrophages and results in the recruitment of CD8+ cells, production of IL- 2 and IFN- $\gamma$, which eventually lead to formation of granulomas $[14,37,38]$.
Ocular lesions due to parasitic colonisation of the lens are very common in rabbits having encephalitozoonosis $[15,39,40]$. The lens capsule may rupture due to disruption of the fibres causing phacoclastic uveitis and zonal granulomatous lens uveitis, as well as cataracts [41]. Most previous studies have reported that the posterior parts of the eye, including the vitreous body, retina, and choroid, are unaffected [42]; however, in the current study, the parasite was observed in the retina.

Some rabbits showed symptoms of polyuria and urinary incontinence. E. cuniculi infection results in renal interstitial lymphocytic proliferation, necrosis of tubular epithelium, and interstitial fibrosis associated with presence of intact or ruptured parasitic cysts [17]. In 

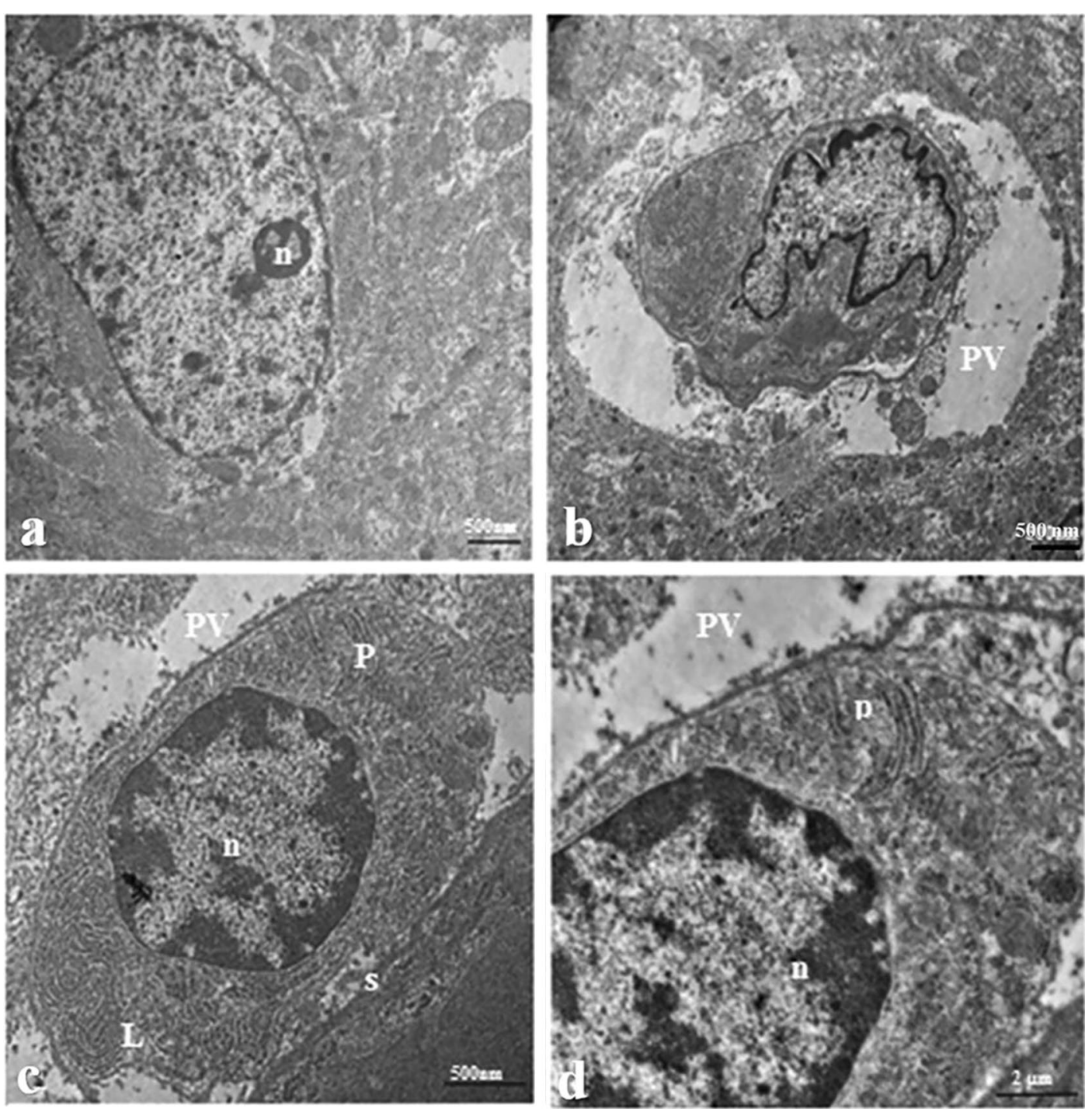

Fig. 5 Transmission electron micrographs of two stages of E. cuniculi in kidney tissue from infected rabbits showing $\mathbf{a}$, $\mathbf{b}$ sporont, $\mathbf{c}$ longitudinal section through mature spore demonstrating lamellar polaroplast and sporal wall, and $\mathbf{d}$ spore with coils of polar tube in a single row $(n=5)(L$ lamellar polaroplast, $n$ nucleus, $P$ polar tube, $P V$ parasitophorous vacuole, $S$ sporal wall)

the present study, renal tissue response was not obvious, although spores and degeneration of tubular epithelial cells were observed.

Hepatic lesions were restricted to mild periportal mononuclear inflammatory cell infiltration and mild vacuolar degeneration but the parasite was observed by Giemsa stained sections. In contrast, other studies have reported moderate to severe lesions in the liver, including periportal nonsuppurative interstitial infiltration, fibrosis and necrosis of the periportal area [17].

To the best of our knowledge, the ultrastructure of $E$. cuniculi stages in the brain and kidneys of rabbits has not been reported previously. The different intracellular stages of E. cuniculi can be discriminated from each other because the parasite undergoes morphological changes [43]. The mature spores of E. cuniculi were found to have a nucleus, lamellar polaroplast, a single row of coiled polar tubes and surrounding spore wall similar to the findings of Vavra and Larsson [44], and Habenbacher et al. [45]. The mature spore of E. cuniculi ranged from $1.75 \times 3.3 \mu \mathrm{m}$, whereas the spore of Encephalitozoon spp. in another study was $1.0-1.5 \times 2.0-2.5 \mu \mathrm{m}$ [9]. The variation between the measurements might be attributed to the tissue type or the stage of parasite development during sample collection and the host [43]. The main feature of differentiation of E. cuniculi from all 


\begin{tabular}{|c|c|c|c|c|c|c|c|c|c|c|c|c|c|c|c|}
\hline & & & & & & & Percent & Identit & & & & & & & \\
\hline & & 1 & 2 & 3 & 4 & 5 & 6 & 7 & 8 & 9 & 10 & 11 & 12 & & \\
\hline & 1 & & 39.2 & 39.2 & 39.2 & 39.2 & 39.2 & 39.2 & 39.2 & 39.2 & 39.2 & 39.2 & 39.2 & 1 & KC513629.E.cuniculi \\
\hline & 2 & 121.6 & & 100.0 & 99.4 & 99.4 & 99.4 & 98.9 & 99.4 & 99.4 & 99.4 & 99.4 & 98.9 & 2 & MH392717.E.cuniculi \\
\hline & 3 & 121.6 & 0.0 & & 99.4 & 99.4 & 99.4 & 98.9 & 99.4 & 99.4 & 99.4 & 99.4 & 98.9 & 3 & KF169729.E.cuniculi \\
\hline & 4 & 120.9 & 0.6 & 0.6 & & 100.0 & 100.0 & 98.3 & 98.9 & 100.0 & 98.9 & 100.0 & 99.4 & 4 & JX185518.E.cuniculi \\
\hline 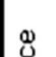 & 5 & 120.9 & 0.6 & 0.6 & 0.0 & & 100.0 & 98.3 & 98.9 & 100.0 & 98.9 & 100.0 & 99.4 & 5 & AF517832.E.cuniculi \\
\hline 点 & 6 & 120.9 & 0.6 & 0.6 & 0.0 & 0.0 & & 98.3 & 98.9 & 100.0 & 98.9 & 100.0 & 99.4 & 6 & AJ005581.E.cuniculi \\
\hline$\stackrel{\substack{0 \\
0}}{3}$ & 7 & 122.4 & 0.0 & 0.0 & 0.6 & 0.6 & 0.6 & & 99.4 & 98.3 & 98.3 & 98.3 & 98.9 & 7 & MK615616.E.cuniculi \\
\hline 范 & 8 & 123.3 & 0.0 & 0.0 & 0.6 & 0.6 & 0.6 & 0.0 & & 98.9 & 98.9 & 98.9 & 99.4 & 8 & X98470.E.cuniculi \\
\hline & 9 & 120.9 & 0.6 & 0.6 & 0.0 & 0.0 & 0.0 & 0.6 & 0.6 & & 98.9 & 100.0 & 99.4 & 9 & X98467.E.cuniculi \\
\hline & 10 & 121.6 & 0.6 & 0.6 & 1.1 & 1.1 & 1.1 & 0.6 & 0.6 & 1.1 & & 98.9 & 98.3 & 10 & L39107.E.cuniculi \\
\hline & 11 & 120.9 & 0.6 & 0.6 & 0.0 & 0.0 & 0.0 & 0.6 & 0.6 & 0.0 & 1.1 & & 99.4 & 11 & L17072.E.cuniculi \\
\hline & 12 & 122.6 & 0.6 & 0.6 & 0.0 & 0.0 & 0.0 & 0.6 & 0.6 & 0.0 & 1.1 & 0.0 & & 12 & L07255.E.cuniculi \\
\hline & & 1 & 2 & 3 & 4 & 5 & 6 & 7 & 8 & 9 & 10 & 11 & 12 & & \\
\hline
\end{tabular}

Fig. 6 Similarity (percent identity) and genetic divergence of $16 \mathrm{~S}$ ribosomal RNA sequences of E. cuniculi from a rabbit in Egypt (representing number, 7) as compared with the most similar reference sequences (GenBank). The 16s ribosomal RNA sequenced in this study is marked and represented as number, 7

other Encephalitozoon spp. is the parasitophorous vacuole (PV). E. cuniculi is the only species of microsporidia known to exist in a septated PV that separates each developing spore [46].

Molecular detection of the Encephalitozoon spp. was done by amplification of the specific $16 S$ gene [30]. The results confirmed E. cuniculi infection in all examined brain, kidney, eye and liver tissues. This result is in accordance with other studies that have suggested that encephalitozoonosis is a systemic disease affecting many organs [47]. The identity matrix for $16 \mathrm{~S}$ rRNA for E. cuniculi presented $99.4 \%$ similarity with E. cuniculi (Donovan sequence) isolated from human thus indicating a potential zoonotic transmission of E. cuniculi circulating in rabbits farms in Egypt.

\section{Conclusions}

Encephalitozoonosis in farmed rabbits was very prevalent in three farms investigated in middle Egypt and associated with a high mortality/culling rate. Sequence analyses revealed a potential zoonotic risk of this infection in Egypt.

\section{Acknowledgements}

The authors appreciate the participation of all rabbit farmers, technical assistants, and veterinarians involved in the data collection, clinical and postmortem examinations.

\section{Prior publication}

Data have not been published previously

\section{Authors' contributions}

EAM and HMS contributed to the design of the study and performed the clinical and postmortem examination. MSK and MA carried out the histopathology, TEM and molecular investigation. DH carried out the sequencing and sequence analysis. All authors drafted the manuscript and participated in the subsequent discussions and revisions of the entire text. All authors read and approved the final manuscript.

\section{Funding}

This research did not receive any specific grant from funding agencies in the public, commercial, or not-for-profit sectors.

\section{Availability of data and materials}

The datasets used and analysed during the current study are available from the corresponding author on reasonable request.

The sequence of the E. cuniculi $16 \mathrm{~S}$ ribosomal RNA gene was deposited in GenBank, Accession number MK615616.

\section{Ethics approval and consent to participate}

The study was approved by the Animal Ethical Committee of Faculty of Veterinary Medicine, Cairo University (VetCU11112018015).

\section{Consent for publication}

The written information assured the respondents that all information would be treated confidentially and that the farmers, by returning the samples, accepted the publication of the results.

\section{Competing interests}

The authors declare that they have no competing interests.

\section{Author details}

${ }^{1}$ Department of Poultry Diseases, Faculty of Veterinary Medicine, Cairo University, PO Box 12211, Giza, Egypt. ${ }^{2}$ Department of Pathology, Faculty of Veterinary Medicine, Cairo University, PO Box 12211, Giza, Egypt. ${ }^{3}$ Department of Zoonoses, Faculty of Veterinary Medicine, Cairo University, PO Box 12211, Giza, Egypt. ${ }^{4}$ Department of Parasitology, Faculty of Veterinary Medicine, Cairo University, PO Box 12211, Giza, Egypt 
Received: 23 April 2019 Accepted: 18 February 2020

Published online: 22 February 2020

\section{References}

1. Han B, Weiss LM. Microsporidia: obligate intracellular pathogens within the fungal kingdom. Microbiol Spectr. 2017;5:2. https://doi.org/10.1128/micro biolspec.FUNK-0018-2016.

2. Wright $\mathrm{JH}$, Craighead EM. Infectious motor paralysis in young rabbits. J Exp Med. 1922;36:135-40.

3. Snowden KF. Zoonotic microsporidia from animals and arthropods with a discussion of human infections. In: Lindsay DS, Weiss LM, editors. World class parasites, opportunistic infections: Toxoplasma, Sarcocystis, and microsporidia. Norwell: Kluwer Academic Publishers; 2004. p. 123-134.

4. Latney LV, Bradley CW, Wyre NR. Encephalitozoon cuniculi in pet rabbits: diagnosis and optimal management. Vet Med Res Rep. 2014;5:169-80.

5. Mathis A, Weber R, Deplazes P. Zoonotic potential of the microsporidia. Clin Microbiol Rev. 2005;18:423-45.

6. Ozkan O, Alcigir ME. Encephalitozoonosis infection in a traditional rabbit farm with neurological manifestations. Vet Parasitol. 2018;262:26-9.

7. Ashmawy Kl, Abuakkada SS, Awad AM. Seroprevalence of antibodies to Encephalitozoon cuniculi and Toxoplasma gondii in farmed domestic rabbits in Egypt. Zoonoses Public Health. 2011:58:357-64.

8. Richardson VCG. Rabbits: health, husbandry, and diseases. Oxford: Blackwell Science; 2000.

9. Weiss LM. Microsporidia, emerging pathogenic protists. Acta Trop. 2001;78:89-102.

10. Maddox JV, Brooks WM, Solter LF. Bioassays of microsporidia. In: Navon A Ascher KRS, editors. Bioassays of entomopathogenic microbes and nematodes. New York: CABI Publishing; 2011.

11. John CC, Ross $\mathrm{CH}$, Harold DA. An investigation of the route and progression of Encephalitozoon cuniculi infection in adult rabbits. J Eukaryot Microbiol. 1979;26:260-5.

12. Wasson K, Peper RL. Mammalian microsporidiosis. Vet Pathol. 2000;37:113-28.

13. Harcourt-Brown FM, Holloway HKR. Encephalitozoon cuniculi in pet rabbits. Vet Rec. 2003;152:427-31.

14. Harcourt-Brown FM. Encephalitozoon cuniculi infection in rabbits. Semin Avian Exot Pet Med. 2004;13:86-93.

15. Felchle LM, Sigler RL. Phacoemulsification for the management of Encephalitozoon cuniculi-induced phacoclastic uveitis in a rabbit. Vet Ophthalmol. 2002;5:211-5.

16. Özkan Ö, Alcigir ME. Subacute stage of Encephalitozoon cuniculi infection in eye lesions of rabbit in Turkey. J Parasitol. 2018;13:301-9.

17. Rodríguez-Tovar LE, Nevárez-Garza AM, Trejo-Chávez A, Hernández-Martínez CA, Hernández-Vidal G, Zarate-Ramos JJ, et al. Encephalitozoon cuniculi: grading the histological lesions in brain, kidney, and liver during primoinfection outbreak in rabbits. J Pathog. 2016. https://doi.org/10.1155/2016/57684 28.

18. Cox JC, Gallichio HA. Serological and histological studies on adult rabbits with recent, naturally acquired encephalitozoonosis. Res Vet Sci. 1978:24:260-1.

19. Franzen C, Nassonova ES, Scholmerich J, Issi IV. Transfer of the members of the genus Brachiola (microsporidia) to the genus Anncaliia based on ultrastructural and molecular data. J Eukaryot Microbiol. 2006;53:26-35.

20. Larsson JR. Molecular versus morphological approach to microsporidian classification. Folia Parasitol. 2005;52:143-4.

21. Verweij JJ, Stensvold CR. Molecular testing for clinical diagnosis and epidemiological investigations of intestinal parasitic infections. Clin Microbiol Rev. 2014;27:371-418

22. Katinka MD, Duprat S, Cornillot E, Méténier G, Thomarat F, Prensier G, et al. Genome sequence and gene compaction of the eukaryote parasite Encephalitozoon cuniculi. Nature. 2001:414:450-3.

23. Pelin A, Moteshareie H, Sak B, Selman M, Naor A, Eyahpaise M-Ė, et al. The genome of an Encephalitozoon cuniculi type III strain reveals insights into the genetic diversity and mode of reproduction of a ubiquitous vertebrate pathogen. Heredity. 2016;116:458-65.

24. Ismail E, Ashraf E. An epidemiological study on endoparasites of domestic rabbits (Oryctolagus cuniculus) in Egypt with special reference to their health impact. Sains Malays. 2018;47:9-18.
25. Harcourt BF Textbook of rabbit medicine Oxford: Educational and Professional Publishing Ltd.; 2002.

26. Hansen J, Perry B. The epidemiology, diagnosis and control of helminth 6 parasites of ruminants. A handbook, vol 171. 2nd ed. Nairobi: ILRAD (International Laboratory for 7 Research on Animal Diseases); 1994.

27. Flecknell PA. BSAVA manual of rabbit medicine and surgery. Gloucester: British Small Animal Veterinary Association; 2000

28. Flecknell P. Laboratory animal anaesthesia. Cambridge: Academic Press; 2015.

29. Suvarna SK, Layton C, Bancroft JD. Bancroft's theory and practice of histological techniques. New York: Churchill Livingstone; 2012.

30. Thurston-Enriquez JA, Watt P, Dowd SE, Enriquez R, Pepper IL, Gerba CHP. Detection of protozoan parasites and microsporidia in irrigation waters used for crop production. J Food Prot. 2002:65:378-82.

31. Abu-Akkada SS, Ashmawy KI, Dweir AW. First detection of an ignored parasite, Encephalitozoon cuniculi, in different animal hosts in Egypt. Parasitol Res. 2015;114:843-50. https://doi.org/10.1007/s00436-014-4247-4.

32. Mancinelli E, Lennox AM. Management of otitis in rabbits. J Exot Pet Med. 2017;26:63-73. https://doi.org/10.1053/j.jepm.2016.10.009.

33. Meyer-Breckwoldt A. Epidemiologische und klinische Untersuchungen zur Encephalitozoonose beim Zwergkaninchen. Diss Vet Med. Hannover; 1996.

34. Künzel F, Gruber A, Tichy A, Edelhofer R, Nell B, Hassan J, et al. Clinical symptoms and diagnosis of encephalitozoonosis in pet rabbits. Vet Parasitol. 2008;151:115-24.

35. Künzel F, Fisher PG. Clinical signs, diagnosis, and treatment of Encephalitozoon cuniculi infection in rabbits. Vet Clin N Am Exot Anim Pract. 2018;21:69-82.

36. Weber R, Deplazes P, Flepp M, Mathis A, Baumann R, Sauer B, et al. Cerebral microsporidiosis due to Encephalitozoon cuniculi in a patient with human immunodeficiency virus infection. N Engl J Med. 1997;336:474-8.

37. Rodriguez-Tovar LE, Speare DJ, Markham RJF. Fish Microsporidia: immune response, immunomodulation, and vaccination. Fish Shellfish Immun. 2011;30:999-1006.

38. Ghosh K, Schwartz D, Weiss LM. Laboratory diagnosis of microsporidia. In: Weiss LM, Becnel JJ, editors. Microsporidia, pathogens of opportunity. Ames: Wiley; 2014. https://doi.org/10.1002/9781118395264.ch17.

39. Wolfer J, Grahn B, Wilcock B, Percy D. Phacoclastic uveitis in the rabbit. Prog Vet Comp Ophthalmol. 1993:3:92-7.

40. Stiles J, Didier E, Ritchie B, Greenacre C, Willis M, Martin C. Encephalitozoon cuniculi in the lens of a rabbit with phacoclastic uveitis: confirmation and treatment. Vet Comp Ophthalmol. 1997;7:233-8.

41. Harcourt-Brown FM. Neurological and locomotor disorders. In: Textbook of rabbit 8/10 medicine. 1st edn. Butterworth-Heinemann: Oxford; 2002. pp. 307-23.

42. Donnelly TM. Encephalitozoon Cuniculi-associated Phacoclastic uveitis in the rabbit: a review. Exot Mam Med Surg. 2003;1:1-3.

43. Bohne W, Ferguson DJ, Kohler K, Gross U. Developmental expression of a tandemly repeated, glycine- and serine-rich spore wall protein in the microsporidian pathogen Encephalitozoon cuniculi. Infect Immun. 2000;68:2268-75.

44. Vavra J, Larsson JIR. Structure of microsporidia. In: Weiss LM, Becnel JJ, editors. Microsporidia: pathogens of opportunity. 1st ed. Ames: Wiley; 2014. p. $1-70$.

45. Habenbacher B, Klang A, Fragner K, Dinhopl N, Künzel F, Weissenböck H. Comparative evaluation of specific methods for labeling of Encephalitozoon cuniculi in paraffin wax embedded tissue samples. J Vet Diagn Invest. 2012;24:370-5.

46. Chu P, West AB. Encephalitozoon (Septata) intestinalis: cytologic, histologic, and electron microscopic features of a systemic intestinal pathogen. Am Clin Pathol. 1966;106:606-14.

47. Von Kücken U, Ludwig HJ, Lange S, Günther H, Dix B, Lange M, et al. Eine generalisierte Erkrankung des Kaninchens durch Enzephalitozoon cuniculi. Mh Vet Med. 1987;42:781-4.

\section{Publisher's Note}

Springer Nature remains neutral with regard to jurisdictional claims in published maps and institutional affiliations. 